\title{
ОЦЕНКА ПРОФЕССИОНАЛЬНОЙ КОМПОНЕНТЫ ЧЕЛОВЕЧЕСКОГО КАПИТАЛА НАУЧНО-ИССЛЕДОВАТЕЛЬСКОГО КОЛЛЕКТИВА
}

\author{
(C) 2020 Седякина Анна Александровна \\ Высшая школа сервиса и торговли \\ Санкт-Петербургский политехнический университет Петра Великого (СПбПУ), \\ Россия, Санкт-Петербург \\ E-mail: aasedyakina@mail.ru \\ (C) 2020 Конников Евгений Александрович \\ кандидат экономических наук, Высшая инженерно-экономическая школа \\ Санкт-Петербургский политехнический университет Петра Великого (СПбПУ), \\ Россия, Санкт-Петербург \\ E-mail: konnikov.evgeniy@gmail.com \\ (c) 2020 Лямин Борис Михайлович \\ Высшая школа сервиса и торговли \\ Санкт-Петербургский политехнический университет Петра Великого (СПбПУ), \\ Россия, Санкт-Петербург \\ E-mail: Lyamin.bm@gmail.com
}

В рамках исследования предложен метод расчета профессиональной компоненты методики оценки человеческого капитала научно-исследовательского коллектива, в которую входят физическая субкомпонента, профессиональная субкомпонента, интеллектуальная и креативная субкомпонента с учетом их весомости рассчитанной при помощи формулы Фишберна. Профессиональная компонента характеризует собой результативную составляющую научно-исследовательской работы работников высшего учебного заведения.

Ключевые слова: человеческий капитал, научно-исследовательский коллектив, инновационная деятельность, методика оценки человеческого капитала научно-исследовательского коллектива

В настоящее время в связи с активным развитием информационных технологий в сфере высшего образования и необходимости генерации инновационных разработок в результате взаимодействия научно-исследовательского коллектива, встает вопрос оценки эффективности работы научно-исследовательского коллектива. Однако, существующие методы оценки человеческого капитала не могут в полной мере быть применимы для оценки человеческого капитала научно-исследовательских коллективов университета [5, 6]. В первую очередь это обусловлено крайней коммерческой направленностью существующих инструментов, выраженной в обязательной оценке стоимости и/или ценности потенциальных результатов. Вместе с тем, результативность инновационной активности носит вариативный характер в рамках инновационной среды университета [1, 4]. Данный факт никак не учитывается существующими инструментами.
Таким образом, необходимо сформировать новый инструмент оценки компонент человеческого капитала научно-исследовательского коллектива - методику оценки профессиональной компоненты человеческого капитала научноисследовательского коллектива.

Разрабатываемая методика оценки человеческого капитала научно-исследовательского коллектива требует формирования инструментов оценки двух ее базовых компонент $[2,3,6]$. Профессиональная компонента может быть дифференцирована на четыре выделенные субкомпоненты. Рассмотрим каждую из приведенных субкомпонент отдельно.

Физическая субкомпонента. В первую очередь рассмотрим данную субкомпоненту, или совокупность физических качеств представителей научно- исследовательского коллектива. Необходимо отметить, что данная субкомпонента не является определяющей в формировании человеческого капитала научно-исследовательского 


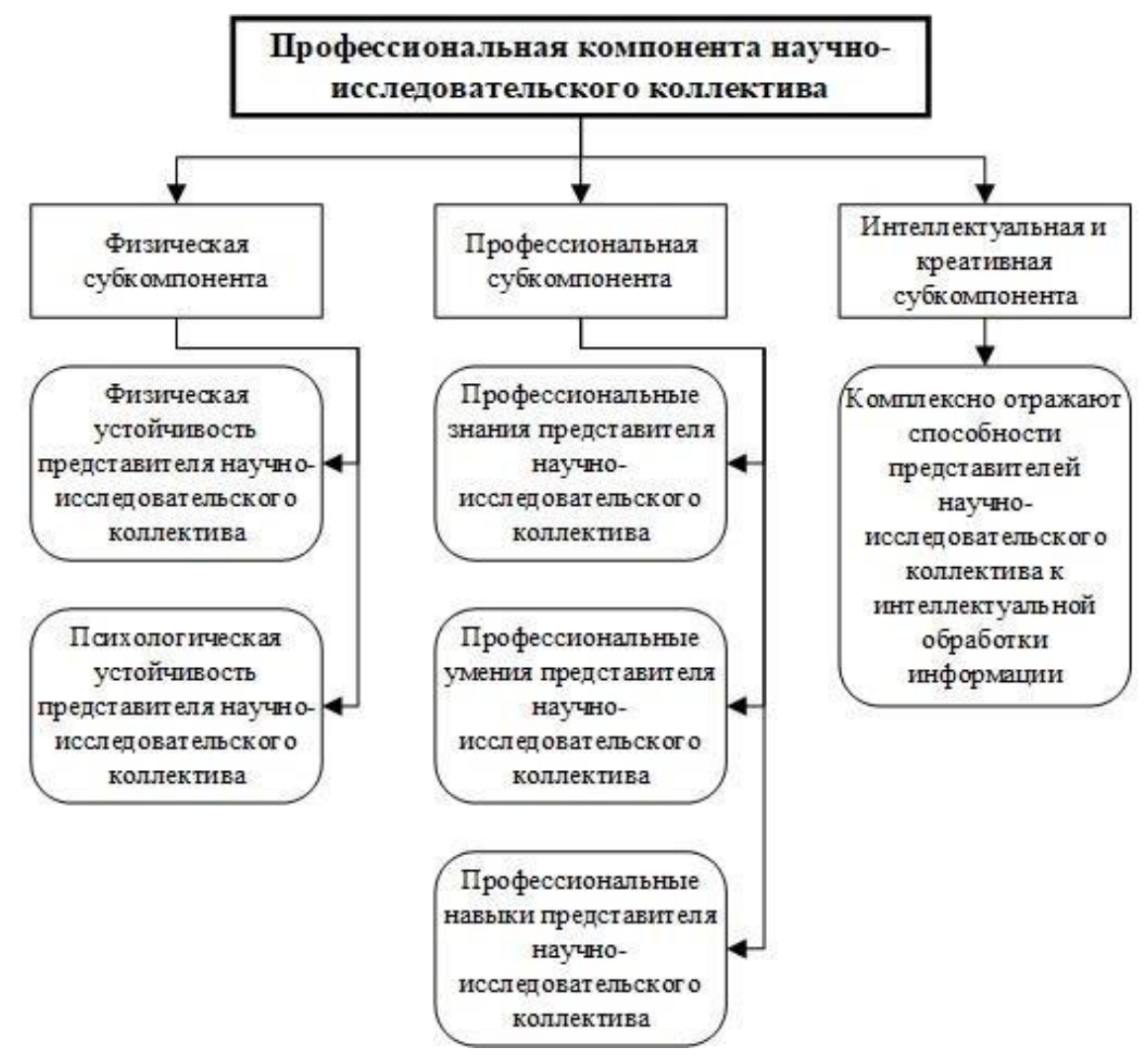

Рисунок 1. Структурные составляющие профессиональной компоненты человеческого капитала научно-исследовательского коллектива

коллектива, однако вне ее учета может быть сформирован физически недееспособный коллектив, который несмотря на высокий уровень профессиональных, интеллектуальных и креативных качеств представителей будет физически не способен вырабатывать необходимой объем результата на единицу времени. Следовательно, физические качества научно- исследовательского коллектива фактически представляют из себя оценку физической кондиции его представителей. При этом, необходимо учитывать, что несмотря на коллективный характер анализируемой деятельности, недостаток физической кондиции хотя бы у одного из представителей может значительно сократить потенциальную эффективность научно-исследовательского коллектива в целом и фактически сделать планируемый исследовательский результат недостижимым. Следовательно, рассматривать данный показатель целесообразно по нижней границе результата, применительно к конкретному научно-исследовательскому коллективу.

Данный комплексный показатель может быть разделен на две составляющие:
1. Физическая устойчивость представителя научно-исследовательского коллектива. Данный показатель характеризует способность представителя научно-исследовательского коллектива осуществлять профессиональную деятельность в течение нормативного периода времени с заданными границами эффективности, вырабатывая тем самым необходимый объем полезного результата на единицу времени.

Установим условное обозначение данного показателя - I ph.s. (индекс физической устойчивости представителя научно-исследовательского коллектива). Единицы измерения данного показателя - баллы.

2. Психологическая устойчивость представителя научно-исследовательского коллектива. Данный показатель отражает способность представителя научно-исследовательского коллектива переносить психологические нагрузки в процессе реализации исследовательского процесса.

При оценке данного показателя учитывается способность объекта исследования работать в условиях стресса, переносить тяготы и лишения при реализации исследовательского процес- 
са, способность устойчиво принимать неудовлетворительный результат и психологически перестраиваться при необходимости трансформации исследовательского процесса. Также, при оценке данного показателя, необходимо учитывать коммуникативные способности объекта исследования, а также наличие у него диагностированных или потенциально имеющихся психических отклонений, однако, данные свойства также косвенно учитываются при оценке совместимости научно- исследовательского коллектива. Значения данного показателя аналогично с предыдущим отрицательно коррелируют с возрастом объекта исследования.

Установим условное обозначение данного показателя $-\mathrm{I}_{\text {ps.s. }}$ (индекс психологической устойчивости представителя научноисследовательского коллектива). Единицы измерения данного показателя - баллы.

Представленные показатели не могут рассматриваться в отрыве друг от друга, что определяет необходимость формирования процедуры комплексной калькуляции интегрального показателя, который может быть назван -«Интегральная оценка физической субкомпоненты человеческого капитала представителя научноисследовательского коллектива» (условное обозначение $-\mathrm{PS}_{\mathrm{n}}$ ). Для целей разработки данной процедуры следует выдвинуть ряд тезисов:

1. Удельный вес влияния каждого из составляющих данную субкомпоненту показателей - одинаковый. Следовательно, удельный вес каждого составляет 0,5 .

2. Данные показатели мультиплицируют воздействие друг друга. Следовательно, математическое определение значения интегрального показателя основано на процедуре умножения, а не сложения значений показателей.

3. Эффект от последствий проявления каждой из компонент в процесс реализации инновационных исследований увеличивается экспоненциально. Таким образом, оценка каждого из показателей, определенная в соответствии с линейной функцией распределения баллов, требует логарифмической обработки.

Для целей оценки применим бальнорейтинговую систему, идентичную для каждого из показателей. Диапазон значений в рамках предлагаемой системы варьируется от 1 до 10 баллом, где:

- 1 - минимальный уровень физической и психологической устойчивости представителя научно-исследовательского коллектива;

- 10 - максимальный уровень физической и психологической устойчивости представителя научно-исследовательского коллектива.

Данную совокупность значений предлагается разделить на следующие диапазоны:

- от 1 до 2 баллов - крайне низкий уровень физической и психологической устойчивости представителя научно-исследовательского коллектива.

- от 3 до 4 баллов - низкий уровень физической и психологической устойчивости представителя научно-исследовательского коллектива.

- от 5 до 6 баллов - средний уровень физической и психологической устойчивости представителя научно-исследовательского коллектива.

- от 7 до 8 баллов - высокий уровень физической и психологической устойчивости представителя научно-исследовательского коллектива.

- от 9 до 10 баллов - показательный уровень физической и психологической устойчивости представителя научно-исследовательского коллектива.

По результатам экспертной оценки каждого из представителей научно- исследовательского коллектива производится логарифмическая обработка полученного результата, позволяющая учесть экспоненциально возрастающий потенциальный ущерб от появления в коллективе физически и психологически неустойчивых представителей. Изначальные экспертные оценки могут быть названы условно-бальными, а получающиеся после процедуры логарифмирования - фактическими. На рисунке 2 представлена процедура перехода от условно бальной оценки физической или психологической устойчивости представителей научно-исследовательского коллектива к фактической.

На рисунке 2 римскими цифрами обозначены диапазоны качественной оценки (трактовки) значений показателей. Как можно видеть, после реализации процедуры логарифмирования число диапазонов и их порядок сохранился неизменным.

Далее производится калькуляция интегральной оценки физической субкомпоненты человеческого капитала каждого представителя научно-исследовательского коллектива. Расчет 
Условно-бальная оценка физической или
психологической устойчивости представителя
научно-исследовательского коллектива (X)
Фактическая оценка физической или психологической устойчивости представителя научно-исследовательского коллектива (Y)
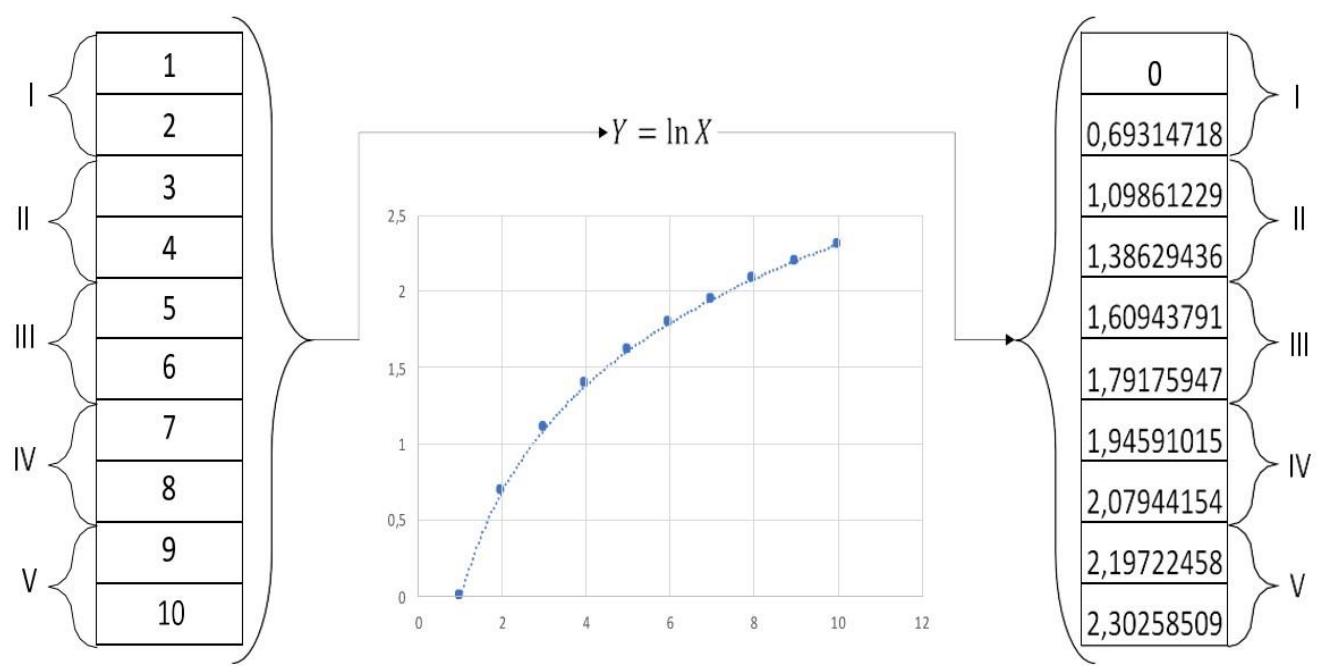

Рисунок 2. Процедура перехода от условно бальной оценки физической или психологической устойчивости представителей научно-исследовательского коллектива к фактической

данного комплексного показателя может быть произведен следующим образом:

$$
P S_{n}=0,5 * \ln \mathrm{I}_{\text {ph.s. }} \text { s }_{n} * \ln \mathrm{I}_{\text {ps. }} \mathrm{s}_{n}
$$

где $\mathrm{PS}_{\mathrm{n}}$ - интегральная оценка физической субкомпоненты профессиональной компоненты человеческого капитала $\mathrm{n}$ представителя научно-исследовательского коллектива;

$\mathrm{I}_{\mathrm{ph} . \mathrm{s}_{\mathrm{n}}}$ - физическая устойчивость $\mathrm{n}$ представителя научно-исследовательского коллектива;

$\mathrm{I}_{\mathrm{ps.s}} \mathrm{n}$ - психологическая устойчивость $\mathrm{n}$ представителя научно-исследовательского коллектива.

По результатам расчета данного показателя для каждого представителя научноисследовательского коллектива производится выбор минимального значения. Данное значение устанавливается в качестве интегральной оценки физической субкомпоненты человеческого капитала научно-исследовательского коллектива (PS).

Консолидированный алгоритм определения интегральной оценки физической субкомпоненты профессиональной компоненты человеческого капитала научно-исследовательского коллектива представлен на рисунке 3.

Таким образом, по результатам расчета максимально возможно числа значений данного показателя в соответствии с максималь- но возможным числом комбинаций научноисследовательского коллектива, управляющим органам предстоит выбрать наилучший в соответствии с критерием максимизации PS.

На рисунке 4 представлена функция распределения значений интегральной оценки физической субкомпоненты человеческого капитала научно-исследовательского коллектива.

Профессиональная субкомпонента профессиональной компоненты человеческого капитала научно-исследовательского коллектива. Данная субкомпонента является одной из определяющих, так как несмотря на инновационный характер рассматриваемых исследований, сам процесс исследований предполагает наличие у участников определенных профессиональных навыков.

Сущностно, профессиональная субкомпонента определяется как совокупность профессиональных знаний, умений и навыков, которые необходимы для своевременного достижения планируемого инновационного результата. Таким образом, профессиональная субкомпонента может быть дифференцирована на три базовые составляющие:

1. Профессиональные знания представителя научно-исследовательского коллектива. Данная характеристика определяется в первую очередь уровнем теоретической подготовки представителя научно-исследовательского коллектива. 


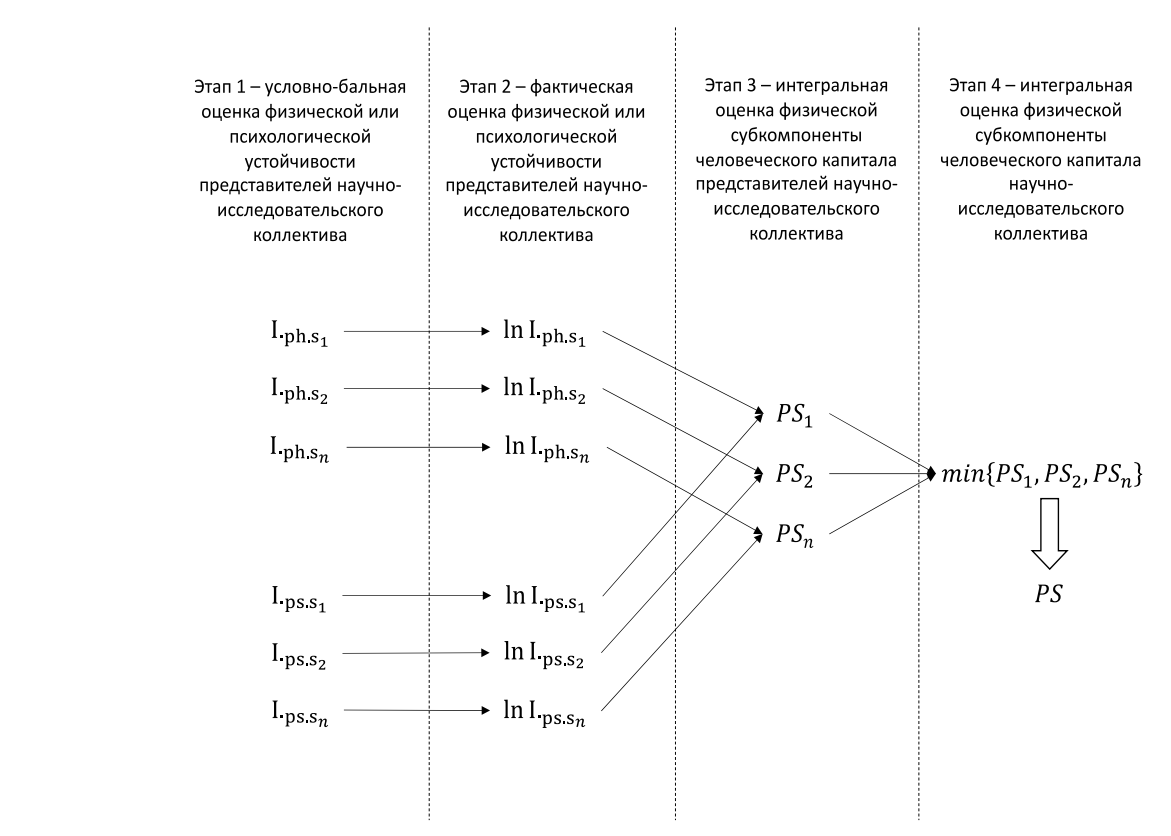

Рисунок 3. Алгоритм определения интегральной оценки физической субкомпоненты человеческого капитала научно-исследовательского коллектива

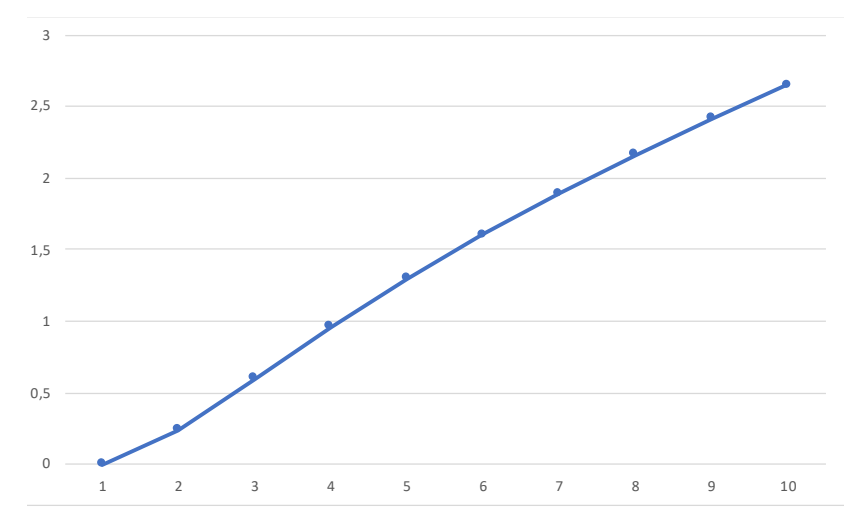

Рисунок 4. Функция распределения значений интегральной оценки физической субкомпоненты человеческого капитала научно-исследовательского коллектива

Уровень знаний с формальной точки зрения может оцениваться уровнем образования. Однако, для целей более эффективной оценки, потенциальным участникам научно-исследовательского коллектива может быть предложено пройти профессиональное тестирования, содержание вопросы, призванные установить именно уровень теоретических знаний соискателя в рамках исследуемой области.

Данный параметр может быть консолидирован в рамках единого показателя - «Уровень профессиональных знаний представителя научно-исследовательского коллектива» (условное обозначение $-\mathrm{I}_{\text {p.k. }}$.
2. Профессиональные умения представителя научно-исследовательского коллектива. Умения определяются способностью представителя научно-исследовательского коллектива применять имеющиеся теоретические знания на практике. Оценка данной характеристики представителя научно-исследовательского коллектива может проводиться на основе собеседования, в рамках которого соискателю предлагается решить конкретный практический кейс в рамках области исследования. Условия выполнения кейса при этом должны быть приближены к условиям проведения будущего исследования.

Данный параметр может быть консолиди- 
рован в рамках единого показателя - «Уровень профессиональных умений представителя научно-исследовательского коллектива» (условное обозначение $-\mathrm{I}_{\mathrm{p.s.}}$.).

3. Профессиональные навыки представителя научно-исследовательского коллектива. Профессиональные навыки предполагают наличие успешного опыта реализации смежных исследований, подобных планируемому исследованию. Оценить данный параметр можно на основе экспертной обработки резюме соискателя, содержавшего ретроспективу его предыдущих исследований.

Данный параметр может быть консолидирован в рамках единого показателя - «Уровень профессиональных навыков представителя научно-исследовательского коллектива» (условное обозначение - Iр.е.).

Необходимо уточнить, что при выборе участников научно-исследовательского коллектива сравнению подвергаются исключительно взаимозаменяемые представители. Это необходимо для целей формирования научноисследовательского коллектива, профессионально способного достигнуть планируемых результатов без необходимости проведения профессиональной переподготовки его участников.

Предложенные показатели предлагается оценивать в рамках установленного ранее диапазона от 1 до 10 баллов, где:

- 1 - минимальный уровень профессиональных знаний, или умений, или навыков представителя научно-исследовательского коллектива;

- 10 - максимальный уровень профессиональных знаний, или умений, или навыков представителя научно-исследовательского коллектива.

Данную шкалу также предлагается разделить на пять равных диапазонов:

1. от 1 до 2 баллов - крайне низкий уровень профессиональных знаний, или умений, или навыков представителя научноисследовательского коллектива.

2. от 3 до 4 баллов - низкий уровень профессиональных знаний, или умений, или навыков представителя научно-исследовательского коллектива.

3. от 5 до 6 баллов - средний уровень профессиональных знаний, или умений, или навыков представителя научно-исследовательского коллектива.

4. от 7 до 8 баллов - высокий уровень профессиональных знаний, или умений, или навыков представителя научно-исследовательского коллектива. Представители данного диапазона характеризуются достаточным уровнем профессиональных знаний, а также опытом успешной реализации альтернативных исследований.

5. от 9 до 10 баллов - показательный уровень профессиональных знаний, или умений, или навыков представителя научноисследовательского коллектива.

Выделенные показатели связаны друг с другом аддитивно, так как являются дополняющими, а не взаимоисключающими или мультиплицирующими. Удельный вес каждого из показателей должен определяться в рамках отдельно взятого исследования, однако, надо отметить, что несмотря на то, что знания являются базисом формирования умений и навыков, именно умения и навыки определяют потенциальную практическую реализуемость исследования, а, следовательно, и достижение инновационного результата. Таким образом, удельный вес предлагается распределить неравномерно. Модель интегральной оценки профессиональной субкомпоненты человеческого капитала представителя научно-исследовательского коллектива примет следующий вид:

$$
\operatorname{Pr}_{n}=0,2 * I_{p . k_{\cdot n}}+0,4 * I_{p . s_{\cdot n}}+0,4 * I_{\text {p.e.n }}
$$

Где:

1. $\mathrm{PrS}_{\mathrm{n}}$ - интегральная оценка профессиональной субкомпоненты человеческого капитала $\mathrm{n}$ представителя научно-исследовательского коллектива;

2. I $\mathrm{I}_{\mathrm{p} . \mathrm{n}}$ - уровень профессиональных знаний $\mathrm{n}$ представителя научно-исследовательского коллектива;

3. I $\mathrm{I}_{\text {p.s.n }}$ - уровень профессиональных умений n представителя научно-исследовательского коллектива;

4. I $\mathrm{I}_{\text {.е.n }}$ - уровень профессиональных навыков n представителя научно-исследовательского коллектива.

По результатам расчета данных частных показателей, производится их суммирование, что позволяет определить интегральную оценку профессиональной субкомпоненты человеческого капитала научно-исследовательского коллектива (PrS). Консолидированный алгоритм 
определения интегральной оценки профессиональной субкомпоненты человеческого капитала научно-исследовательского коллектива представлен на рисунке 5.

Интеллектуальная и креативная субкомпоненты. В завершении необходимо рассмотреть интеллектуальную и креативную субкомпоненту профессиональной компоненты человеческого капитала научно-исследовательского коллектива. Данные субкомпоненты являются наиболее вариативными и комплексными для целей оценки.

Интеллектуальная субкомпонента (IS) является отражением способностей представителей научно-исследовательского коллектива к интеллектуальной обработке информации. Классическим способом определения данного параметра является тест IQ. Однако, для данного исследования предлагается использовать введенную ранее 10-ти бальную шкалу, где 1 - наименьший уровень интеллектуальной субкомпоненты представителя научно-исследовательского коллектива, а 10 - максимальный уровень интеллектуальной субкомпоненты представителя научно-исследовательского коллектива. Предложенные ранее диапазоны сохраняются. При этом, оценку данного параметра предлагается производить одномерно и экспертно, так как ее систематизация может привести к линейным искажениям экспертного восприятия объекта оценки.

В рамках данного исследования предлагается рассматривать данный параметр с аддитивной точки зрения и представить его в виде суммы оценок данного параметра относительно представителей научно-исследовательского коллектива. Таким образом, модель интегральной оценки интеллектуальной субкомпоненты человеческого капитала научно-исследовательского коллектива примет следующий вид:

$$
I S=\sum_{1}^{n} I S_{n}
$$

Где:

1. $\mathrm{IS}_{\mathrm{n}}$ - интегральная оценка интеллектуальной субкомпоненты человеческого капитала $\mathrm{n}$ представителя научно-исследовательского коллектива;

2. $\mathrm{n}$ - число участников научноисследовательского коллектива.

В качестве механизма определения креативной субкомпоненты человеческого капитала научно-исследовательского коллектива (CS) предлагается использовать предложенный ранее механизм определения интеллектуальной субкомпоненты. Данное математическое уравнение обосновывается структурной сложностью оцениваемого предмета, и, как следствие, необ-

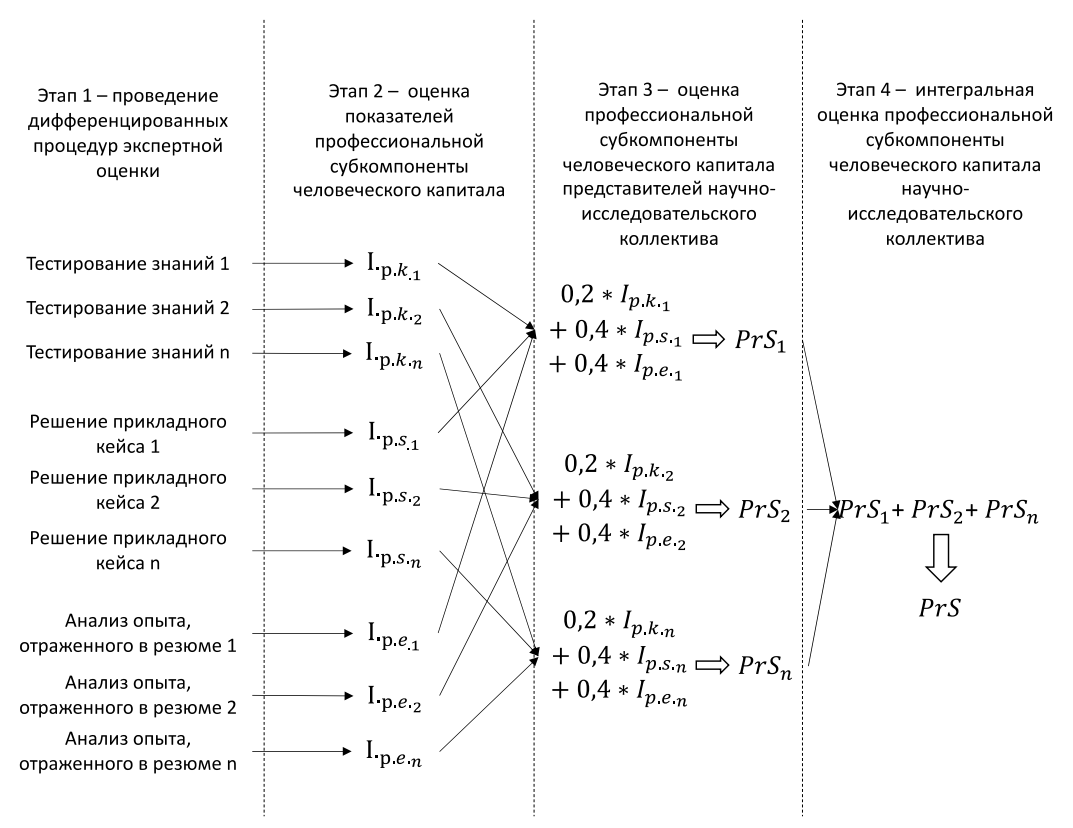

Рисунок 5. Алгоритм определения интегральной оценки профессиональной субкомпоненты человеческого капитала научно-исследовательского коллектива 
ходимость ухода от линейных искажений экспертного восприятия объекта. Таким образом, модель интегральной оценки креативной субкомпоненты человеческого капитала научноисследовательского коллектива примет следующий вид:

$$
C S=\sum_{1}^{n} C S_{n}
$$

Где:

1. $\mathrm{CS}_{\mathrm{n}}$ - интегральная оценка креативной субкомпоненты человеческого капитала $\mathrm{n}$ представителя научно-исследовательского коллектива;

2. $\mathrm{n}$ - число участников научно-исследовательского коллектива.

На основе обработки полученных результатов может быть определено значение профессиональной компоненты человеческого капитала научно-исследовательского коллектива (К). При этом необходимо учитывать дифференциацию удельного веса каждой из субкомпонент. Для целей эффективного распределения удельного веса предлагается использовать подход Фишберна, и градировать предложенные субкомпоненты. Следовательно, значение профессио- нальной компоненты человеческого капитала научно-исследовательского коллектива может быть определено следующим образом:

$$
K=0,1 * P S+0,4 * P r S+0,3 * I S+0,2 * C S
$$

Данный показатель является базисом для оценки человеческого капитала научноисследовательского коллектива и определения предиктивной результативности процесса генерации инновационных результатов. Однако, как отмечалось ранее, данный показатель может приращаться или сокращаться за счет коммуникативной совместимости научноисследовательского коллектива.

Таким образом, в рамках исследования предложен метод расчета профессиональной компоненты методики оценки человеческого капитала научно-исследовательского коллектива, в которую входят физическая субкомпонента, профессиональная субкомпонента, интеллектуальная и креативная субкомпонента с учетом их весомости рассчитанной при помощи формулы Фишберна. Профессиональная компонента характеризует собой результативную составляющую научно-исследовательской работы работников высшего учебного заведения.

\section{Библиографический список}

1. Забелин Б. Ф. [и др.]. Интегрированная система планирования и управления реализацией проектов // Экономические науки. 2020. № 185. С. 111-114.

2. Калинина О. В., Фирова С.В.Планирование инновационной деятельности на основе управления стратегическими параметрами инвестирования // Научно-технические ведомости Санкт-Петербургского государственного политехнического университета. Экономические науки. 2019. № 5 (12).

3. Кобичева А. М., Калинина О. В., Родионов Д. Г. Университет в роли инновационной корпорации // Российский экономический интернет-журнал. 2019. № 4. С. 73.

4. Лямин, Б.М.Шевченко. Н.Н. Особенности стратегического управления инновационными проектами в современных условиях // Научное обозрение: теория и практика. 2018. (12). С. 36-43.

5. Седякина А. А., Конников Е. А. Методика оценки совместимости научно-исследовательского коллектива // Экономические науки. 2020. № 188. С. 77-87.

6. Седякина А. А., Лямин Б. М., Калинина О.В. Формы стимулирования инновационной деятельности в университетах 2019.С. 643-646. 